\title{
Biosafety and biosecurity requirements for Orientia spp. diagnosis and research: recommendations for risk-based biocontainment, work practices and the case for reclassification to risk group 2
}

Stuart D. Blacksell ${ }^{1,2,3^{*}}$ D, Matthew T. Robinson ${ }^{2,3}$, Paul N. Newton ${ }^{2,3}$, Soiratchaneekorn Ruanchaimun ${ }^{1}$,

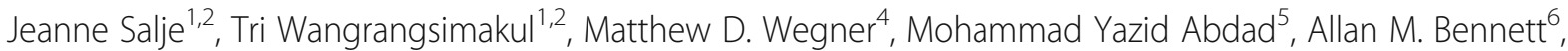
Allen L. Richards ${ }^{7}$, John Stenos ${ }^{8}$ and Nicholas P. J. Day ${ }^{1,2}$

\begin{abstract}
Scrub typhus is an important arthropod-borne disease causing significant acute febrile illness by infection with Orientia spp.

Using a risk-based approach, this review examines current practice, the evidence base and regulatory requirements regarding matters of biosafety and biosecurity, and presents the case for reclassification from Risk Group 3 to Risk Group 2 along with recommendations for safe working practices of risk-based activities during the manipulation of Orientia spp. in the laboratory.

We recommend to reclassify Orientia spp. to Risk Group 2 based on the classification for RG2 pathogens as being moderate individual risk, low community risk. We recommend that low risk activities, can be performed within a biological safety cabinet located in a Biosafety Level (BSL) 2 core laboratory using standard personal protective equipment. But when the risk assessment indicates, such as high concentration and volume, or aerosol generation, then a higher biocontainment level is warranted. For, the majority of animal activities involving Orientia spp., Animal BSL 2 (ABSL2) is recommended however where high risk activities are performed including necropsies, Animal BSL (ABSL3) is recommended.
\end{abstract}

Keywords: Orientia, Scrub typhus, Biosafety, Biocontainment, Risk group

\section{Background}

Scrub typhus is an important arthropod-borne disease causing significant acute febrile illness in the AsiaPacific region [1] caused by Orientia tsutsugamushi. Other members of scrub typhus group orientiae [2] include Candidatus Orientia chuto from United Arab Emirates [3] and Kenya [4], and the incompletely characterized orientiae that cause scrub typhus in Chile [5-7].

\footnotetext{
* Correspondence: stuart@tropmedres.ac

${ }^{1}$ Mahidol-Oxford Tropical Medicine Research Unit, Faculty of Tropical

Medicine, Mahidol University, Bangkok 10400, Thailand

${ }^{2}$ Centre for Tropical Medicine and Global Health, Nuffield Department of

Medicine, Churchill Hospital, Oxford OX3 7FZ, UK

Full list of author information is available at the end of the article
}

Orientia spp. are members of the family Rickettsiaceae in the order Rickettsiales, are Gram-negative, obligate, intracellular bacteria and are transmitted by arthropod vectors $[8,9]$.

The laboratory diagnosis of scrub typhus requires the detection of antibodies against and/or nucleic acids of $O$. tsutsugamushi using serological techniques and PCR, respectively $[9,10]$. In vitro culture of Orientia spp. is generally not required for diagnostic purposes, though culture is required to provide the raw materials for diagnostic assays, whole genome sequencing, and the study of growth characteristics. The in vitro or in vivo culture of Orientia spp. has the potential hazard of laboratory-

(c) The Author(s). 2019 Open Access This article is distributed under the terms of the Creative Commons Attribution 4.0 International License (http://creativecommons.org/licenses/by/4.0/), which permits unrestricted use, distribution, and reproduction in any medium, provided you give appropriate credit to the original author(s) and the source, provide a link to the Creative Commons license, and indicate if changes were made. The Creative Commons Public Domain Dedication waiver (http://creativecommons.org/publicdomain/zero/1.0/) applies to the data made available in this article, unless otherwise stated. 
acquired infections (LAIs) of staff by means of parenteral inoculation such as accidental self-inoculation, cut, animal bite or scratch, or exposure to aerosols from laboratory procedures or accidents [11-13]. Furthermore, Orientia spp. are sensitive to antibiotics including doxycycline and azithromycin $[14,15]$.

Using a risk-based approach, this review examines the evidence base, regulatory requirements and current practice, regarding biosafety and biosecurity practises, and argues for the reclassification from Risk Group 3 to Risk Group 2 along with recommendations for safe practices of risk-based activities during the manipulation of Orientia spp. in the laboratory.

\section{Risk group classification and biocontainment regulations for Orientia spp. research}

Risk Groups (RG) (known as Hazard Groups (HG) in the United Kingdom) are used as biosafety "shorthand" to quantify the degree of hazard associated with a pathogen or toxin. Although there is no universal RG classification there is general agreement amongst countries on RG principles (Table 1). Briefly, RG1 pathogens are those of low individual and community risk. RG2 pathogens represent the largest group and have the characteristics of moderate individual risk and low community risk, and there is general agreement that they are classified as those that "can cause human disease and might be a hazard to workers and effective treatment and preventive measures are available (antibiotics or vaccine) and the risk of spread of diseases in the community caused by these pathogens is low". RG3 pathogens are considered high individual risk with limited/moderate community risk and "likely to cause serious disease and may present a risk of spreading to the community, but there is usually effective prophylaxis or treatment available" (Table 1).

At present, all members of Orientia spp. and the related Rickettsia spp. are classified as RG3 pathogens or equivalent in the United States, United Kingdom, Australia, Singapore, Germany, Switzerland, Belgium, and the European Union [17, 19]. As such, significant biosafety controls have been placed on their manipulation, propagation and storage. Interestingly, in many regions where the disease is endemic, there are few statutory regulations or guidelines regarding biosafety, as well as a lack of clear guidance on the level of biocontainment required for laboratory work on Orientia spp. In the absence of clear local regulations, government regulatory authorities often look to the USA or UK regulations, or elsewhere, to provide the basis for biosafety and biocontainment. There is often an imperative from donors to meet specific biosafety and biocontainment guidelines prior to the disbursement of funds. The following is a short description of the guidelines and regulations as specified by national regulators and a summary is provided in Table 2.

Physical biocontainment is generally classified as biosafety levels (BSL1-4) although there are differing national standards and regulations. To increase standardisation, the World Health Organization (WHO) has recently revised the WHO Laboratory Biosafety Manual (LBM 4th edition) using a risk-based approach [24] with three levels of biocontainment; 1) Core, 2) Heightened Control Measures (HCM) and 3) Maximum containment.

\section{USA regulations}

Orientia tsutsugamushi and Rickettsia spp. (e.g. R. prowazekii, R. typhi, R. rickettsii, Rickettsia conorii, R. akari, $R$. australis, $R$. sibirica, and $R$. japonica) are classified as RG3 organisms and are detailed in the BMBL 5th edition [21] in regards to their control as follows (p197-198). "BSL2 practices, biocontainment equipment, and facilities are recommended for non-propagative laboratory procedures, including serological and fluorescent antibody procedures, and for the staining of impression smears. BSL3 practices, biocontainment equipment, and facilities are recommended for all other manipulations of known or potentially infectious materials, including necropsy of experimentally infected animals and trituration of their tissues, and inoculation, incubation, and harvesting of embryonated eggs or cell cultures. Animal BSL (ABSL) 2 practices, biocontainment equipment, and facilities are recommended for the holding of experimentally infected mammals other than arthropods. ABSL3 practices, biocontainment equipment, and facilities are recommended for animal studies with arthropods naturally or experimentally infected with rickettsial agents of human disease. Several species, including $R$. montanensis, $R$. rhipicephali, $R$. bellii, and $R$. canadensis, are not known to cause human disease and may be handled under BSL2 conditions."

\section{UK regulations}

In the UK, the Advisory Committee on Dangerous Pathogens (ACDP) advises the Health and Safety Executive (HSE) on aspects of hazards and risks to workers and others from pathogen exposure pathogens. All Rickettsia spp. (R. akari, R. canadensis, $R$. conorii, $R$. montanensis, $R$. prowazekii, $R$. rickettsii, $R$. (Orientia) tsutsugamushi, $R$. sennetsu, $R$. typhi) are classified as HG 3 pathogens in the Approved List of Biological agents 2013 (ACDP/ HSE) [20]. The Control of Substances Hazardous to Health Regulations 2002 (Schedule 3, Part I, Paragraph 3 (4) (b)) state that "the minimum biocontainment level... shall be... level 3 for activities which involve working with a Group 3 biological agent" and so, in the UK, all work with confirmed Orientia spp. must be conducted in a Biocontainment Level ( $\mathrm{CL}=\mathrm{UK}$ BSL equivalent $) 3$ 
Table 1 Examples of worldwide biological Risk Group classifications

\begin{tabular}{|c|c|c|c|c|}
\hline $\begin{array}{l}\text { Country or } \\
\text { region }\end{array}$ & Risk Group 1 & Risk Group 2 & Risk Group 3 & Risk Group 4 \\
\hline $\begin{array}{l}\text { Australian/ } \\
\text { New } \\
\text { Zealand } \\
\text { Standard } \\
{[16]}\end{array}$ & $\begin{array}{l}\text { Low individual and community } \\
\text { risk } \\
\text { A microorganism that is unlikely } \\
\text { to cause human or animal } \\
\text { disease. }\end{array}$ & $\begin{array}{l}\text { Moderate individual risk, limited } \\
\text { community risk } \\
\text { A microorganism that is unlikely } \\
\text { to be a significant risk to laboratory } \\
\text { workers, the community, livestock, } \\
\text { or the environment; laboratory } \\
\text { exposures may cause infections, } \\
\text { Effective treatment and preventive } \\
\text { measures are available, and the } \\
\text { risk of spread is limited. }\end{array}$ & $\begin{array}{l}\text { High individual risk, limited to } \\
\text { moderate community risk } \\
\text { A microorganism that usually } \\
\text { causes serious human or } \\
\text { animal disease and may present } \\
\text { a significant risk to laboratory } \\
\text { workers. } \\
\text { It could present a limited to } \\
\text { moderate risk if spread in the } \\
\text { community or the environment, } \\
\text { but there are usually effective } \\
\text { preventive measures or treatment } \\
\text { available. }\end{array}$ & $\begin{array}{l}\text { High individual and } \\
\text { community risk } \\
\text { A microorganism that } \\
\text { usually produces life- } \\
\text { threatening human or } \\
\text { animal disease, represents } \\
\text { a significant risk to } \\
\text { laboratory workers and } \\
\text { may be readily } \\
\text { transmissible from one } \\
\text { individual to another. } \\
\text { Effective treatment and } \\
\text { preventive measures are } \\
\text { not usually available. }\end{array}$ \\
\hline
\end{tabular}

Belgium

[17]

harmful for the environment or
the man and the environment
at the laboratory scale.
This class includes, beside
organisms whose harmlessness
was proven, strains which can
be allergens and opportunistic
pathogens

Canada Low individual and community

[18] risk

A microorganism, nucleic acid, or protein that is either a) not capable of causing human or animal disease; or b) capable of causing human or animal disease, but unlikely to do so. Those capable of causing disease are considered pathogens that pose a low risk to the health of individuals or animals, and a low risk to public health and the animal population.
Micro -organisms that can cause human disease and might be a hazard for directly exposed persons; they are unlikely to spread to the community. There is usually effective prophylaxis or treatment available.

Micro -organisms that can cause severe human disease and present a serious hazard for directly exposed persons. They may present a risk of spreading to the community. There is usually effective prophylaxis or treatment available.

Micro -organisms that cause severe human disease and are a serious hazard for directly exposed persons. They may present a high risk of spreading to the community.

There is usually no effective prophylaxis or treatment available.

Moderate individual risk, low community risk

A pathogen or toxin that poses a moderate risk to the health of individuals or animals, and a low risk to public health and the animal population.

These pathogens are able to cause serious disease in a human or animal but are unlikely to do so. Effective treatment and preventive measures are available and the risk of spread of diseases caused by these pathogens is low.
High individual risk, low community risk

A pathogen that poses a high risk to the health of individuals or animals, and a low risk to public health.

These pathogens are likely to cause serious disease in a human or animal.

Effective treatment and preventive measures are usually available and the risk of spread of disease caused by these pathogens is low for the public.

The risk of spread to the animal population, however, can range from low to high depending on the pathogen.

Biological agent means one that

European Biological agent means one Economic that is unlikely to cause human

Community disease.

\section{Directive}

2000/54/EC

and

Directive

90/679/EEC

[19]

Germany

[19]
Biomaterials, where it is unlikely that they cause disease in humans can cause human disease and

might be a hazard to workers; it is unlikely to spread to the community; there is usually effective prophylaxis or treatment available.

Biomaterials that can cause human disease and might be a hazard to workers;

Dispersal in the population is unlikely;

Effective prophylaxis or treatment is normally possible
Biological agent means one that can cause severe human disease and present a serious hazard to workers; it may present a risk of spreading to the community, but there is usually effective prophylaxis or treatment available.

Biomaterials, which cause severe human disease and present a serious hazard to workers; The risk of spread to the community, but there is usually effective prophylaxis or treatment available
High individual risk, high community risk

A pathogen that poses a high risk to the health of individuals or animals and a high risk to public health. These pathogens are likely to cause serious disease in a human or animal, which can often lead to death. Effective treatment and preventive measures are not usually available and the risk of spread of disease caused by these pathogens is high for the public.

The risk of spread of disease to the animal population, however, ranges from low to high, depending on the pathogen.

Biological agent means one that causes severe human disease and is a serious hazard to workers; it may present a high risk of spreading to the community; there is usually no effective prophylaxis or treatment available.

Biological agents which cause severe human disease and are a serious hazard to workers;

The risk of spread in the population is high under certain circumstances; there is usually no effective 
Table 1 Examples of worldwide biological Risk Group classifications (Continued)

\begin{tabular}{|c|c|c|c|c|}
\hline $\begin{array}{l}\text { Country or } \\
\text { region }\end{array}$ & Risk Group 1 & Risk Group 2 & Risk Group 3 & Risk Group 4 \\
\hline & & & & prophylaxis or treatment. \\
\hline $\begin{array}{l}\text { United } \\
\text { Kingdom } \\
{[20]}\end{array}$ & $\begin{array}{l}\text { Unlikely to cause human } \\
\text { disease }\end{array}$ & $\begin{array}{l}\text { Can cause human disease and may } \\
\text { be a hazard to employees; } \\
\text { It is unlikely to spread to the } \\
\text { community and there is usually } \\
\text { effective prophylaxis or treatment } \\
\text { available. }\end{array}$ & $\begin{array}{l}\text { Can cause severe human disease } \\
\text { and may be a serious hazard to } \\
\text { employees; } \\
\text { It may spread to the community, } \\
\text { but there is usually effective } \\
\text { prophylaxis or treatment available. }\end{array}$ & $\begin{array}{l}\text { Causes severe human } \\
\text { disease and is a serious } \\
\text { hazard to employees; } \\
\text { It is likely to spread to the } \\
\text { community and there is } \\
\text { usually no effective } \\
\text { prophylaxis or treatment } \\
\text { available }\end{array}$ \\
\hline
\end{tabular}

laboratory. The position is less straightforward when specimens from suspected cases of Orientia spp. infection are handled in a clinical laboratory for diagnostic purposes (Table 2).

\section{Australia}

In Australia, laboratories are governed by the Australian/New Zealand Standards AS/NZS which outline the safety principles in laboratories, AS/NZS 2243.3.2010 Safety in Laboratories Part 3: Microbiological Safety and Biocontainment [16]. Clinical specimens with unconfirmed microbial aetiology are regarded as low risk and handled at BSL2. However, once a high-risk pathogen has been isolated from a specimen, it must then be handled at a higher biocontainment level. Although rickettsiae are mentioned as RG3 pathogens there is no mention of Orientia spp. in the Standard. However, Orientia spp. were historically labelled as a Rickettsia spp. and this perhaps indicates the need for this standard to be updated.

\section{Singapore}

The legislation that governs the possession, use, import, transhipment, transfer, and transportation of biological agents in Singapore falls under the Biologicals and Toxins Act (BATA), that was originally enacted in 2005 [22]. Rickettsial organisms of the genus Rickettsia are classified within the act as First Schedule biological agent meaning "Risk Group 3 Biological Agents which can cause serious disease which is of high risk to the individual". Members of the genus Orientia are not specifically mentioned but they are generally viewed as similar to Rickettsia spp. and thus require the same restrictions. Although the legislation does not specify the restrictions of the environment where a biological agent should be worked on, organisms are organised into "Schedules" that share similar restrictions (i.e., First Schedule agents may require BSL3, Second Schedule agents may require BSL4, Third and Fourth Schedule may require BSL2). This allows for the testing of normally accepted RG3 pathogens such as Rickettsia and Orientia spp. from non-amplified diagnostic samples to potentially be performed in a BSL2 environment should the appropriate approval be granted after a review of the planned work environment and the conduct of appropriate risk assessments.

\section{Thailand}

The Royal Thai Government enacted the Pathogens and Animal Toxins Act in 1982 that is administered by the Ministry of Public Health and focuses on the regulation and security of pathogens and toxins [23]. It has subsequently been updated in 2001 and 2015 with the latter superseding the previous iterations. Pathogens are designated into 4 risk groups, numbered 1 to 4 , corresponding to low, moderate, high, and very high risk, respectively. These pathogens were further defined in the official Announcement of the Ministry of Public Health "List of controlled pathogens under section 18 (of the Act)" 2017 [25]. Group 2 pathogens (moderate risk) can be handled under BSL2 conditions and include $R$. africae, R. bellii, R. canadensis, R. felis, R. helvetica, $R$. honei, $R$. japonica, $R$. montanensis, $R$. parkeri, $R$. quintana, $R$. rhipicephali, $R$. sennetsu and $R$. slovaca. Group 3 pathogens include $R$. akari, $R$. australis, $R$. conorii, $R$. prowazekii, $R$. rickettsii, $R$. sibirica, $R$. (Orientia) tsutsugamushi, and R. typhi. Routine diagnostic laboratory processing within hospital laboratories can be performed in BSL-2 laboratories with strict adherence to Good Laboratory Practice guidelines. Culturing with the aim of producing large amounts of bacteria should be performed in BSL3 laboratories or equivalent safety level (BSL2 enhanced).

\section{Other countries and regions}

Germany, Switzerland, Belgium [17] and the European Union classify Orientia tsutsugamushi as an RG3 pathogen [19]. Canada does not provide a RG classification in its Pathogen Safety Data Sheet resource [18].

\section{Risk-assessment for Orientia spp.}

The case for reclassification of Orientia spp. to RG2 using a risk-based justification.

Using the broad classification for RG2 pathogens of moderate individual risk, low community risk that "can 
Table 2 Biocontainment and mitigation regulations for Orientia spp.

\begin{tabular}{|c|c|c|c|c|}
\hline \multirow[b]{2}{*}{ Country } & \multirow[b]{2}{*}{ Regulations } & \multirow[b]{2}{*}{ Activity } & \multicolumn{2}{|l|}{ Laboratory studies } \\
\hline & & & Low-risk & Enhanced-risk \\
\hline USA & $\begin{array}{l}\text { BMBL5th Ed. } \\
{[21]}\end{array}$ & Clinical & $\begin{array}{l}\text { "BSL2 practices, biocontainment equipment, and } \\
\text { facilities are recommended for non-propagative la } \\
\text { boratory procedures, including serological and fluor } \\
\text { escent antibody procedures, and for the staining of } \\
\text { impression smears. }\end{array}$ & $\begin{array}{l}\text { New species are being described frequently and } \\
\text { should be evaluated for appropriate biocontainment } \\
\text { on a case-by-case basis. Because of the proven value } \\
\text { of antibiotic therapy in the early stages of rickettsial } \\
\text { infection, it is essential that laboratories have an ef } \\
\text { fective system for reporting febrile illnesses in labora } \\
\text { tory personnel, medical evaluation of potential cases } \\
\text { and, when indicated, institution of appropriate anti } \\
\text { biotic therapy. }\end{array}$ \\
\hline
\end{tabular}

Research $R$ prowazekii; $R$ typhi (R. mooseri); Orientia (Rickettsia) tsutsugamushi and Spotted Fever Group agents of human disease; $R$ rickettsii, $R$ conorii, $R$ akari, $R$ australis, $R$ siberica, and $R$ japonicum - BSL3 practices, biocontainment equipment, and facilities are recommended for all other manipulations of known or potentially infectious materials, including necropsy of experimentally infected animals and trituration of their tissues, and inoculation, incubation, and harvesting of embryonated eggs or cell cultures.

R. montana, R. rhipicephali, $R$. belli, and $R$. canada,are not known to cause human disease and may be handled under BSL2 conditions.

Research

$\begin{array}{ll}\text { Australia } & \text { AS/NZS } \\ & \text { 2243.3.2010 }\end{array}$ [16]
Clinical

Clinical specimens are generally regarded as low risk and handled under BSL2 conditions. Very few laboratories attempt cell culture isolation of Orientia spp. from clinical specimens and the recovery rate of viable organisms is very low. However, once an isolate has been identified the specimen must be subsequently be handled at BSL3.

Research Inactivated Orientia isolates can be handled at BSL2

Singapore BATA 2005 [22] Clinical For samples where the diagnosis is unknown, diagnostic testing that does not result in amplification of the pathogen tested for can be performed in a BSL2 environment.

Laboratories conducting clinical diagnostics of Rickettsia and Orientia spp. are required to conduct risk inert and non-infectious. handled at BSL3.
Microbiology laboratories offering a diagnostic service to a hospital will from time to time isolate a hazard group 3 pathogen when working at CL2. Once identified, work on such isolates and on material known or suspected to contain hazard group 3 biological agents must be conducted in a $\mathrm{CL} 3$ laboratory, unless the agent is specifically identified as an exemption in the ACDP Second supplement 2000."

"It is recognised that pathogens may be present in specimens which, had they been identified, would need to be handled at a higher level of containment. If such pathogens are identified during the course of work at CL 2, all further work on the specimen or associated specimens must be conducted at a higher biocontainment level, usually $\mathrm{CL} 3$ or exceptionally $\mathrm{CL}$ 4. If higher biocontainment level facilities are not available, the isolate should be sent to an appropriate laboratory, or be destroyed. If it is suspected, for example from a clinical history, that a specimen may contain hazard group 3 biological agents, all work on that specimen or other specimens from that patient must be conducted at CL3."

Rickettsia spp (specified as the following R. akari, $R$ canada, $R$ conorii, $R$ montana, $R$ prowazekii, $R$ rickettsii, $R$ (Orientia) tsutsugamushi, $R$ sennetsu, $R$ typhi) are classified as a Hazard Group 3 Pathogen "the minimum biocontainment level... shall be...level 3 for activities which involve working with a Group 3 biological agent" and so in the UK all work with known Orientia spp. must be conducted in a CL3/BSL 3 laboratory.

There may be a need for further characterisation of a clinical isolate with respect to typing and as such these activities need to be performed at BSL3.

All viable Orientia/rickettsial agents need to be

In enhanced risk situation, the work environment will need to be BSL3. This covers all work that involves "live" organisms in the sample or culture, whereby no prior approved steps have been applied to the material that would render the pathogen assessment and provide appropriate measures and 
Table 2 Biocontainment and mitigation regulations for Orientia spp. (Continued)

\begin{tabular}{|c|c|c|c|c|}
\hline \multirow[b]{2}{*}{ Country } & \multirow[b]{2}{*}{ Regulations } & \multirow[b]{2}{*}{ Activity } & \multicolumn{2}{|l|}{ Laboratory studies } \\
\hline & & & Low-risk & Enhanced-risk \\
\hline & & & $\begin{array}{l}\text { safeguards to significantly reduce risk of infection of } \\
\text { laboratory staff. }\end{array}$ & \\
\hline & & Research & $\begin{array}{l}\text { For research work on live samples and cultures, the } \\
\text { work environment is required to be at BSL3. } \\
\text { Large scale culture }(>10 \mathrm{I}) \text { is prohibited without } \\
\text { written authorization of the Director of Medical } \\
\text { Services, Ministry of Health Singapore. }\end{array}$ & \\
\hline \multirow[t]{2}{*}{ Thailand } & $\begin{array}{l}\text { Pathogens and } \\
\text { Animals Toxins } \\
\text { Act } 2015 \text { [23] }\end{array}$ & Clinical & $\begin{array}{l}\text { Routine diagnostic laboratory processing within } \\
\text { hospital laboratories can be performed in BSL-2 } \\
\text { laboratories with strict adherence to Good } \\
\text { Laboratory Practice guidelines. }\end{array}$ & $\begin{array}{l}\text { Culturing with the aim of producing large amounts } \\
\text { of bacteria should be performed in BSL3 laboratories } \\
\text { or equivalent safety level (BSL2 enhanced). }\end{array}$ \\
\hline & & Research & As per clinical activity & \\
\hline
\end{tabular}

BSL biological safety level, ACDP advisory committee on dangerous pathogens, $C L$ biocontainmentlevel, AS/NZS Australian/New Zealand Standards, BATA biologicals and toxins act

cause human disease and might be a hazard to workers and effective treatment and preventive measures are available (antibiotics or vaccine) and the risk of spread of diseases in the community caused by these pathogens is low", a strong argument can be made to reclassify Orientia spp. to RG2. Certainly, Orientia spp. do not fit the characteristics of RG3 pathogens which are considered high individual risk, limited/moderate community risk with the key difference being the risk of spread of the disease in the community. We therefore recommend reclassification of Orientia spp. to RG2 by all countries.

\section{Recommended risk assessments for Orientia spp. research activities}

Risk associated with Orientia spp. individual research activities and laboratory procedures.

Laboratory activities associated with risk of accidental exposure of personnel and the environment to Orientia spp. include (1) the processing of clinical specimens from scrub typhus patients and, (2) in vitro culture of Orientia spp. in mammalian cell cultures or embryonated chicken eggs and associated downstream manipulations including centrifugation, harvesting of cells and supernatants and, carrying cultures to and from incubators to a Biological Safety Cabinet (BSC) [11-13].

LOW risk activities for both laboratory staff and environmental contamination in case of an accident would be small-scale processing of suspected scrub typhus patient samples such as initial in vitro inoculation or subsequent passage of patient samples on to cell cultures with a guideline of a total of $\leq 100 \mathrm{ml}$ (in a single or multiple culture vessels) at a concentration of $\leq 10^{6} \mathrm{cfu} / \mathrm{ml}$ Orientia spp. organisms. This may also include small-scale passaging of reference cultures.

MEDIUM risk activities may include those such as medium-scale passaging of reference cultures or medium-scale passage of clinical Orientia spp. isolates to increase the viable organism concentration thereby increasing the risk to the laboratory staff whilst maintaining a low risk of escape to the environment in case of an accident. Suggested guidelines for medium risk activities would be incubation and manipulation guideline of a total of $\leq 500 \mathrm{ml}$ (in a single or multiple culture vessels) at a concentration of $\leq 10^{6} \mathrm{cfu} / \mathrm{ml}$ Orientia spp. organisms.

HIGH risk activities involve increased volume and concentration of the Orientia spp. organisms manipulated such as in the case of reagent production which may involve large-scale production of highly concentrated Orientia spp. as well as manipulation with increased inherent risk such centrifugation and concentration techniques, as there is an increased risk to the laboratory staff and of escape to the environment in case of an accident. Suggested guidelines for high risk activities would be incubation and manipulation guideline of a total of $>500 \mathrm{ml}$ (in a single or multiple culture vessels) at a concentration of $>10^{6} \mathrm{cfu} / \mathrm{ml}$ Orientia spp. organisms.

The determination of the risk level should be made by a biosafety professional in conjunction with stakeholders including principal investigator and laboratory management as the risk mitigation measures are likely to have significant infrastructure and financial implications.

Risk associated with Orientia spp. during experimental animal activities

Experimental infection of animals (vertebrates and invertebrates) with Orientia spp. presents a different range of infection risks than those of laboratory activities. Vertebrates used for experimental infections are predominantly rodents [26, 27], guinea pigs [28] and non-human primates $[29,30]$ while chiggers (Leptotrombidium spp.) [29] have been the dominant genus of invertebrates. The risks may be broadly characterised as aerosol and parenteral exposures. Aerosol exposures would normally be 
associated with necropsy activities, cage and bedding changing (if agents is secreted in urine and faeces), and infectious waste exposures [31]. Parenteral exposures would normally be due to bites, cuts, and scratches from animals or sharp equipment $[11,13$, 31]. All such activities if performed on a small-scale would normally be considered MEDIUM risk. However, if the number of animals significantly increase or larger animal species are used, then risk would increase to HIGH. As mentioned above, in the case of increased risk activities, this determination should be made by a biosafety professional in conjunction with stakeholders. For MEDIUM risk procedures where there is minimal aerosol generation then Animal Biosafety Level 2 (ABSL2) is recommended however where HIGH risk activities are performed including necropsies, Animal Biosafety Level 3 (ABSL3) is recommended. Mitigation strategies for medium- and high-risk animal activities based on the US BMBL 5th edition regulations [21] are presented in Table 3.

Table 3 Mitigation strategies for medium- and high-risk animal activities based on the US BMBL 5th edition regulations [21]

\begin{tabular}{|c|c|c|}
\hline Mitigation strategy & Experimentally-infected animals & $\begin{array}{l}\text { Arthropods and necropsy of } \\
\text { infected animals }\end{array}$ \\
\hline Personnel protection & $\begin{array}{l}\text { Experimental Orientia spp. and any work on isolates of the organism would be } \\
\text { undertaken in a Class II BSC }{ }^{\text {a }} \text { meaning that the risk of airborne exposure of staff } \\
\text { is minimal. If a Class II BSC is not available and there is a risk of aerosol } \\
\text { exposure, staff should be fitted with and wear an N-95 respirator. } \\
\text { All work on samples that are suspected of containing Orientia spp. and any } \\
\text { work on isolates of the organism would be undertaken by staff wearing gloves } \\
\text { with avoidance of sharps wherever possible, minimising the risk of inoculation. } \\
\text { Outer garments, such as lab coats or Tyvek overalls, should be worn during } \\
\text { work which has the potential to produce splashes or aerosols of bacteria. } \\
\text { Workers can be provided with a medical alert card to take to medical clinics } \\
\text { should an accidental exposure occur. This card contains information about the } \\
\text { nature of the work, the agent being worked with, and appropriate medical } \\
\text { management to help inform and educate health care providers who may not } \\
\text { be familiar with scrub typhus or laboratory animals. }\end{array}$ & $\begin{array}{l}\text { As for experimentally-infected } \\
\text { animals }\end{array}$ \\
\hline Primary containment & Class II BSC & $\begin{array}{l}\text { As for experimentally-infected } \\
\text { animals }\end{array}$ \\
\hline Secondary biocontainment & ABSL2 & BSL3/ABSL3 \\
\hline Animal Handling & $\begin{array}{l}\text { Appropriate PPE for the species of animal should be worn. Working with } \\
\text { non-human primates (NHP) poses a risk of infection with Macacine } \\
\text { herpesvirus and PPE should be utilized to prevent infection with this virus. } \\
\text { If using rodents, the risk of bites can be mitigated by acclimatizing the animals } \\
\text { to handling or by wearing bite-resistant gloves. } \\
\text { Non-human primates should also be trained and acclimatized to the various } \\
\text { procedures encountered in the course of the protocol. Use of pole, collar, and } \\
\text { chair restraint devices minimize direct animal handling for examination, } \\
\text { injections/inoculations, and treatments. If this is not possible, NHP should be } \\
\text { anesthetized using an appropriate anaesthetic protocol for the procedure. } \\
\text { Necropsy of scrub typhus-infected animals should be undertaken in appropriate } \\
\text { facilities based on the infection status of the animal. If the animal is infectious, } \\
\text { (i.e. active bacteraemia or infection), the animal should be necropsied in a Class } \\
\text { II BSC and/or within an ABSL3 or BSL3 laboratory. If the animal is non-infectious, } \\
\text { standard necropsy procedures can be followed. }\end{array}$ & $\begin{array}{l}\text { As for experimentally-infected } \\
\text { animals }\end{array}$ \\
\hline $\begin{array}{l}\text { Disinfection (any of the } \\
\text { following options) }\end{array}$ & $\begin{array}{l}\text { Autoclave }-121^{\circ} \mathrm{C} \text { for } 30 \text { min } \\
\text { Dry heat - } 160-170{ }^{\circ} \mathrm{C} \text { for at least } 60 \text { min } \\
\text { Chemical (At least } 30 \text { min contact time) } \\
1 \% \text { Virkon (surfaces) or } 2 \% \text { Virkon (liquids) } \\
1 \% \text { sodium hypochlorite } \\
70 \% \text { ethanol, } \\
\text { Glutaraldehyde } \\
\text { Formaldehyde } \\
\text { Quaternary ammonium disinfectants. }\end{array}$ & $\begin{array}{l}\text { As for experimentally-infected } \\
\text { animals }\end{array}$ \\
\hline Training & $\begin{array}{l}\text { Additional, specialized training should occur when working with laboratory } \\
\text { animals. The type of training may vary depending on the regulatory requirements } \\
\text { of the country in which the work is being performed. } \\
\text { Staff working with NHP should receive training about Macacine herpesvirus since } \\
\text { this is an extremely dangerous zoonotic disease that can lead to death if not treated. } \\
\text { Staff should be trained and proficient in animal handling, restraint, sample } \\
\text { collection, treatment administration, necropsy procedures, and other experimental } \\
\text { procedures on animals before working with scrub typhus-infected animals. }\end{array}$ & $\begin{array}{l}\text { As for experimentally-infected } \\
\text { animals }\end{array}$ \\
\hline
\end{tabular}




\section{Recommendations for risk-based biocontainment levels for Orientia spp. laboratory activities}

Risk-based assessment of laboratory activities for Orientia spp., when classified as a RG2 pathogen, do not support the need for BSL3 biocontainment for LOW-risk routine, low-volume culturing of Orientia spp. and downstream activities and most MEDIUMrisk activities. Therefore, these activities can be performed at BSL2 biocontainment level in a BSC with standard Personal Protective Equipment (PPE) which would be consistent with WHO HCM. However, for HIGH-risk activities where high concentrations and large volumes of live organisms are involved such as in the case of reagent production, the risk assessment may suggest performing the activities at a higher level of secondary containment, such as BSL3 containment, and PPE may need to include respirators if primary biocontainment equipment (e.g. BSC) are not available or easily able to be used. Stocks of reference cultures at high concentrations require sufficient levels of physical biosecurity including locked freezers, stored behind locked doors with restricted/vetted personnel access to prevent the theft of pure cultures that may be used for nefarious purposes. Risk-based recommendations for biocontainment and associated mitigation strategies for low- and high-risk Orientia spp. laboratory activities are presented in Table 4.

\section{Discussion}

Until now, Orientia spp. and Rickettsia spp. have been classified as RG3 pathogens resulting in substantial controls placed on their growth, handling and storage. This RG3 classification may have evolved from association with the more pathogenic $R$. rickettsii and $R$. prowazekii -which were classified by the United States as Biological Select Agents in 2007 due to their biothreat status [21, 32], however, only $R$. prowazekii retains this status in the current Select Agents list [33]. Orientia spp. are classified as RG3 pathogens by the USA, European Union, Australia, New Zealand, Belgium, Germany, Switzerland and Thailand [19, 25]. While Orientia spp. and many Rickettsia spp. have the potential to cause serious infections, it is difficult to justify their status as RG3 pathogens because they do not spread by person-to-person contact and are amenable to antibiotic treatment.

Further confusion around biosafety requirements for Orientia spp. laboratory investigations is the fallacy that RG status is equivalent to biocontainment level [24]. This misinterpretation has resulted in the incorrect assumption that BSL3 biocontainment is a mandated requirement for all Orientia spp. manipulations, without considering the procedural risks. BSL3 biocontainment laboratories fundamentally differ from BSL2 biocontainment as they provide directional airflow via a negative pressure gradient and HEPA filtered exhaust air that

Table 4 Risk-based recommendations for biocontainment and associated mitigation strategies for low- and high-risk laboratory activities

\begin{tabular}{|c|c|c|}
\hline Mitigation strategy & Low $^{a}$ to Medium ${ }^{b}$-risk laboratory activities & High-risk laboratory activities ${ }^{c}$ \\
\hline Personnel protection & $\begin{array}{l}\text { Gown } \\
\text { Gloves } \\
\text { Eye protection } \\
\text { Covered shoes } \\
\text { Avoidance of sharps }\end{array}$ & $\begin{array}{l}\text { Respiratory protection } \\
\text { Gown } \\
\text { Gloves } \\
\text { Eye protection } \\
\text { Covered shoes } \\
\text { Avoidance of sharps }\end{array}$ \\
\hline Primary containment & $\begin{array}{l}\text { Class II BSC (annually certified) } \\
\text { Aerosol generating procedures (i.e., centrifugation) } \\
\text { devices with bioseal (gaskets buckets and } \\
\text { corresponding lids (screw or clip type). } \\
\text { Buckets may only be opened in the BSC }\end{array}$ & $\begin{array}{l}\text { Class II BSC (annually certified) } \\
\text { Aerosol generating procedures (i.e., centrifugation) } \\
\text { devices with bioseal (gaskets buckets and } \\
\text { corresponding lids (screw or clip type). Buckets may } \\
\text { only be opened in the BSC }\end{array}$ \\
\hline Secondary biocontainment & Biosafety Level 2 or Core & Biosafety Level 3 or Heightened Control Measures \\
\hline Disinfection (any of the following options) & $\begin{array}{l}\text { Autoclave }-121^{\circ} \mathrm{C} \text { for } 30 \text { min } \\
\text { Dry heat }-160-170^{\circ} \mathrm{C} \text { for at least } 60 \text { min } \\
\text { Chemical (at least } 30 \text { min contact time) } \\
1 \% \text { Virkon (surfaces) or } 2 \% \text { Virkon (liquids) } \\
1 \% \text { sodium hypochlorite } \\
70 \% \text { ethanol } \\
\text { Glutaraldehyde } \\
\text { Formaldehyde } \\
\text { Quaternary ammonium disinfectants }\end{array}$ & $\begin{array}{l}\text { Autoclave }-121^{\circ} \mathrm{C} \text { for } 30 \text { min } \\
\text { Dry heat }-160-170^{\circ} \mathrm{C} \text { for at least } 60 \text { min } \\
\text { Chemical (at least } 30 \text { min contact time) } \\
1 \% \text { Virkon (surfaces) or } 2 \% \text { Virkon (liquids) } \\
1 \% \text { sodium hypochlorite } \\
70 \% \text { ethanol } \\
\text { Glutaraldehyde } \\
\text { Formaldehyde } \\
\text { Quaternary ammonium disinfectants }\end{array}$ \\
\hline Training & $\begin{array}{l}\text { Staff need to be trained and demonstrate } \\
\text { proficiency in GMPP }\end{array}$ & $\begin{array}{l}\text { Staff need to be trained and demonstrate proficiency } \\
\text { in GMPP }\end{array}$ \\
\hline
\end{tabular}

BSC biological safety cabinet, GMPP good microbiological practises and procedures

${ }^{a}$ Low-risk $-\leq 100 \mathrm{ml}$ (in a single or multiple culture vessels) at a concentration of $\leq 10^{6} \mathrm{cfu} / \mathrm{ml}$ Orientia spp. organisms

${ }^{b}$ Medium-risk - $\leq 500 \mathrm{ml}$ (in a single or multiple culture vessels) at a concentration of $\leq 10^{6} \mathrm{cfu} / \mathrm{ml}$ Orientia spp. organisms

${ }^{\mathrm{C}} \mathrm{High}$-risk - $>500 \mathrm{ml}$ (in a single or multiple culture vessels) at a concentration of $>10^{6} \mathrm{cfu} / \mathrm{ml}$ Orientia spp. organisms 
provides protection to the outside environment from aerosol contamination in the event of a catastrophic laboratory accident. A consequence of the need for complex engineering solutions to provide adequate BSL3 biocontainment is that such laboratories are expensive to build, maintain, and manage. Furthermore, such laboratories typically have high electricity costs to maintain heating, ventilation and air-conditioning (HVAC) requirements which further compounded by the regulatory necessity for single pass non-recirculated air. Building and operating a BSL3 laboratory places financial strain on already stretched budgets, and those wishing to maintain regulatory compliance often choose not perform such activities at a lower biocontainment levels for fear of not complying with national laws, funder requirements, or incorrectly perceiving the activities to be too "high risk" to be performed.

It is likely that the requirement for BSL3 biocontainment has had unintended consequence of impeding scrub typhus research and vaccine development [34]. Laboratory and regulatory administrators have taken an overly cautious attitude to the regulatory aspects of research on Orientia spp. and other rickettsial pathogens. This has resulted in the proliferation of highbiocontainment laboratories in both relatively-wealthy and developing countries. The need for highbiocontainment laboratories for Orientia spp. propagation has been overstated and the mistaken requirement to perform all such work in BSL3 laboratory facilities through rules imposed by national governments, or foreign institutions providing donor funds has further compounded the issue.

The evidence presented here demonstrates that work with Orientia spp. and Rickettsia spp. requires a riskbased consideration when selecting biosafety and biocontainment controls. Using a blanket RG3/BSL3 approach is inappropriate and restrictive except when the risks are clearly high and the controls justified. The WHO LBM 4th edition [24], uses a risk-based approach and stipulates that only high-risk activities be performed in HCM laboratories, which may include (but is not restricted to) BSL3 laboratory facilities.

The evidence from scrub typhus LAI reports [13, 31], clearly supports the proposal that low risk activities, can be safely performed within a BSC located in BSL2 core laboratory (i.e., HCM laboratory). When warranted, the requirement for increased secondary containment, PPE and enhanced practices should be maintained. This is supported by the fact that scrub typhus LAIs have not been reported for nearly 20 years [13], and exposure of laboratory staff to infectious materials and their products are ameliorated by rigorous biological safety mitigation strategies through administrative controls including a focus on good microbiological practises and procedures, competency assessment, was well as judicious selection of PPE.

\section{Conclusions}

We recommend the reclassification of Orientia spp. to RG2 based on the classification of RG2 pathogens as being moderate individual risk and low community risk. Furthermore, using a risk-based approach, we recommend that low risk activities can be performed within a BSC located in a BSL2 core laboratory (i.e., HCM laboratory) and high-risk activities, such as those involving aerosol generation or high bioburden of bacteria, would require the use of BSL3 laboratory facilities. The majority of animal activities involving Orientia spp. would still require ABSL3 containment. Consideration should also be given to the risk-group reclassification of selected Rickettsia spp. using the same risk-based approach.

\section{Abbreviations \\ ABSL: Animal Biological Safety Level; BSC: Biological Safety Cabinet; \\ BSL: Biological Safety Level; GMPP: Good Microbiological Practises and Procedures.; HCM: Heightened Control Measures; LAl: Laboratory-acquired infection; LBM: Laboratory Biosafety Manual; PPE: Personal Protective equipment; RG: Risk Group; WHO: World Health Organization}

\section{Acknowledgments}

Not applicable.

\section{Disclaimer}

The opinions or assertions contained herein are the private views of the author, and are not to be construed as official, or as reflecting true views of the Department of the Army or the Department of Defense.

\section{Authors' contributions}

The manuscript concept was devised by SB, PN and ND. SB contributed the main draft of the manuscript. SB, MR, TW, AR, AB and JeS contributed to the sections on risk assessment. MW contributed to the sections on Animal Biosafety. SR and TW contributed to the sections on regulations in Thailand. MA contributed to the sections on regulations in Singapore. JoS contributed to the sections on regulations in Australia. SB, AR, AB contributed to the sections on regulations in the United Kingdom and the United States. All authors contributed to the writing of the manuscript. All authors read and approved the final manuscript.

\section{Funding}

Stuart D. Blacksell, Matthew T. Robinson, Paul N. Newton, Tri Wangrangsimakul, Jeanne Salje and Nicholas P.J. Day are funded by the Wellcome Trust of the United Kingdom. The funders had no role in the design of the study and collection, analysis, and interpretation of data and in writing the manuscript.

\section{Availability of data and materials}

All data generated or analysed during this study are included in this published article.

Ethics approval and consent to participate Not applicable.

Consent for publication

Not applicable.

Competing interests

The authors declare that they have no competing interests. 


\section{Author details}

${ }^{1}$ Mahidol-Oxford Tropical Medicine Research Unit, Faculty of Tropical Medicine, Mahidol University, Bangkok 10400, Thailand. ${ }^{2}$ Centre for Tropical Medicine and Global Health, Nuffield Department of Medicine, Churchill Hospital, Oxford OX3 7FZ, UK. ${ }^{3}$ Lao-Oxford-Mahosot Hospital-Wellcome Trust Research Unit (LOMWRU), Mahosot Hospital, Vientiane, Lao People's Democratic Republic. ${ }^{4}$ Armed Forces Research Institute of Medical Sciences (AFRIMS), Bangkok 10400, Thailand. ${ }^{5}$ Infectious Disease Research Laboratory, National Centre for Infectious Diseases, Singapore, Singapore. ${ }^{6}$ Public Health England, Biosafety, Air and Water Microbiology Group, Porton, Salisbury, Wiltshire SP4 OJG, UK. 'Department of Preventive Medicine and Biostatistics, Uniformed Services University of the Health Sciences, Bethesda, MD 20814, USA. ${ }^{8}$ Australian Rickettsial Reference Laboratory, Geelong Hospital, Geelong, Victoria 3220, Australia.

Received: 5 July 2019 Accepted: 22 November 2019

Published online: 10 December 2019

\section{References}

1. Phongmany S, Rolain JM, Phetsouvanh R, et al. Rickettsial infections and fever, Vientiane, Laos. Emerg Infect Dis. 2006;12(2):256-62.

2. Jiang J, Richards AL. Scrub Typhus: No Longer Restricted to the Tsutsugamushi Triangle. Trop Med Infect Dis. 2018;3(1).

3. Izzard L, Fuller A, Blacksell SD, et al. Isolation of a novel Orientia species (O. chuto sp. nov.) from a patient infected in Dubai. J Clin Microbiol. 2010; 48(12):4404-9.

4. Masakhwe C, Linsuwanon P, Kimita G, et al. Identification and Characterization of Orientia chuto in Trombiculid Chigger Mites Collected from Wild Rodents in Kenya. J Clin Microbiol. 2018;56(12).

5. Balcells ME, Rabagliati R, Garcia P, et al. Endemic scrub typhus-like illness. Chile Emerg Infect Dis. 2011;17(9):1659-63.

6. Weitzel T, Dittrich S, Lopez J, et al. Endemic scrub typhus in South America. N Engl J Med. 2016;375(10):954-61.

7. Weitzel T, Martinez-Valdebenito C, Acosta-Jamett G, Jiang J, Richards AL, Abarca K. Scrub Typhus in Continental Chile, 2016-2018(1). Emerg Infect Dis. 2019;25(6):1214-7.

8. Kelly DJ, Richards AL, Temenak J, Strickman D, Dasch GA. The past and present threat of rickettsial diseases to military medicine and international public health. Clin Infect Dis. 2002;34(Suppl 4):S145-69.

9. Luce-Fedrow A, Mullins K, Kostik AP, St John HK, Jiang J, Richards AL. Strategies for detecting rickettsiae and diagnosing rickettsial diseases. Future Microbiol. 2015;10(4):537-64.

10. Koh GC, Maude RJ, Paris DH, Newton PN, Blacksell SD. Diagnosis of scrub typhus. Am J Trop Med Hyg. 2010;82(3):368-70.

11. Pike RM. Laboratory-associated infections: summary and analysis of 3921 cases. Health Lab Sci. 1976:13(2):105-14.

12. Singh K. Laboratory-acquired infections. Clin Infect Dis. 2009;49(1):142-7.

13. Blacksell SD, Robinson MT, Newton PN, Day NPJ. Laboratory-acquired scrub typhus and murine typhus infections: the argument for risk-based approach to biosafety requirements for Orientia tsutsugamushi and Rickettsia typhi laboratory activities. Clin Infect Dis. 2019;68(8):1413-9.

14. Kim YS, Yun HJ, Shim SK, Koo SH, Kim SY, Kim S. A comparative trial of a single dose of azithromycin versus doxycycline for the treatment of mild scrub typhus. Clin Infect Dis. 2004;39(9):1329-35.

15. Kim YS, Lee HJ, Chang M, Son SK, Rhee YE, Shim SK. Scrub typhus during pregnancy and its treatment: a case series and review of the literature. Am J Trop Med Hygiene. 2006;75(5):955-9.

16. Standards Australia. AS/NZS 2243.3.2010 Safety in Laboratories Part 3: Microbiological Safety and Containment.

17. Belgian Biosafety Server. Belgian risk group classifications. https://www. biosafety.be/content/tools-belgian-classification-micro-organisms-basedtheir-biological-risks Accessed 21 Mar 2019.

18. Canada Government. Pathogen Safety Data Sheets. https://www.canada.ca/ en/public-health/services/infectious-diseases.html. Accessed 14 Mar 2019.

19. American Biological Safety Association. Risk group database. https://my.absa. org/tiki-index.php. Accessed 20 Mar 2019.

20. Advisory Committee on Dangerous Pathogens. In: The Approved List of biological agents. London: Health and Safety Executive. http://www.hse.gov. uk/pubns/misc208.pdf Accessed 20 Mar 2019

21. U.S. Department of Health and Human Services, Public Health Service, Centers for Disease Control and Prevention, and National Institutes of
Health. Biosafety in Microbiological and Biomedical Laboratories. 5th ed. Washington: U. S. Government Printing Office.

22. Singapore Government. In: Biologicals and Toxins Act (Chapter 24A). https:// sso.agc.gov.sg/Act/BATA2005. Accessed 14 Mar 2019.

23. Pathogens and Animal Toxins Act. Government Gazette 2015; Vol 132(Part 80a): 9-38.

24. Kojima K, Makison Booth C, Summermatter K, et al. Risk-based reboot for global lab biosafety. Science. 2018;360(6386):260-2.

25. Announcement of the Ministry of Public Health - List of Controlled Pathogens under Section 18 of the Pathogens and Animal Toxins Act. Government Gazette 2017; 134(74): 6-77.

26. Carley JG, Doherty RL, Derrick EH, Pope JH, Emanuel ML, Ross CJ. The investigation of fevers in North Queensland by mouse inoculation, with particular reference to scrub typhus. Australas Ann Med. 1955;4(2):91-9.

27. Smadel JE, Rights FL, Jackson EB. Studies on scrub typhus; preparation of formalinized vaccines from tissues of infected mice and rats. Proc Soc Exp Biol Med. 1946;61:308-13.

28. Kouwenaar W, Esseveld $\mathrm{H}$. The nature of immunity against scrub typhus in Guinea-pigs. Doc Neerl Indones Morbis Trop. 1949;1(1):34-40.

29. Chattopadhyay S, Jiang J, Chan TC, et al. Scrub typhus vaccine candidate Kp r56 induces humoral and cellular immune responses in cynomolgus monkeys. Infect Immun. 2005;73(8):5039-47.

30. Paris DH, Chattopadhyay S, Jiang J, et al. A nonhuman primate scrub typhus model: protective immune responses induced by pKarp47 DNA vaccination in cynomolgus macaques. J Immunol. 2015;194(4):1702-16.

31. Blacksell SD, Siengsanan-Lamont J. A review of laboratory-acquired infections in the Asia-Pacific: understanding risk and the need for improved biosafety for veterinary and zoonotic diseases. Trop Med Infect Dis. 2018; 3(2):36-46.

32. Azad AF. Pathogenic rickettsiae as bioterrorism agents. Clin Infect Dis. 2007; 45(Suppl 1):S52-5.

33. Federal Select Agent Program. Select Agent and Toxins list. HHS and USDA Select Agents and Toxins 7 CFR Part 331, 9 CFR Part 121, and 42 CFR Part 73. Available at: https://www.selectagents.gov/SelectAgentsandToxinsList. html Accessed 14 Mar 2019.

34. Wurtz N, Grobusch MP, Raoult D. Negative impact of laws regarding biosecurity and bioterrorism on real diseases. Clin Microbiol Infect. 2014;20: 507-15.

\section{Publisher's Note}

Springer Nature remains neutral with regard to jurisdictional claims in published maps and institutional affiliations.
Ready to submit your research? Choose BMC and benefit from:

- fast, convenient online submission

- thorough peer review by experienced researchers in your field

- rapid publication on acceptance

- support for research data, including large and complex data types

- gold Open Access which fosters wider collaboration and increased citations

- maximum visibility for your research: over $100 \mathrm{M}$ website views per year

At $\mathrm{BMC}$, research is always in progress.

Learn more biomedcentral.com/submissions 